\title{
Existential Psychotherapy Supervision: The Supervisor's Perspective
}

Journal of Humanistic Psychology

$|-2|$

(C) The Author(s) 2018

Article reuse guidelines: sagepub.com/journals-permissions DOI: $10.1177 / 0022167818802905$ journals.sagepub.com/home/jhp

(S)SAGE

\section{Sara Silva' and Daniel Sousa ${ }^{2}$ (iD}

\begin{abstract}
Supervision is a cross-disciplinary practice among various professional groups. This study focuses on clinical supervision as a practice linked to psychology and psychotherapy. The literature highlights the need to expand and consolidate knowledge in this area. Specifically, in the few existing approaches to research on existential supervision, the need for the systematization of knowledge is clear. The use of qualitative methods is recognized as an approach that is likely to enrich knowledge of supervision. Objective: The aim of this study was to explore the theme of clinical supervision, particularly as it relates to existential psychotherapy, from the supervisor's perspective to assess insights from the experience of each participant. Method: The three participants are both existential psychotherapists and supervisors that apply the same approach, in group mode, in the context of psychotherapist training. The data were collected using phenomenological interviews. A comprehensive analysis of the transcripts of the interviews was performed using the phenomenological method. Results: Emerging themes presented a general meaning structure that represents eidetic dimensions and how they are related. The eidetic dimensions, relationship and responsiveness, arise in the existential approach as the foundational and promotional aspects of successful supervision.
\end{abstract}

\section{Keywords}

supervision research, psychotherapy supervision, existential, psychotherapy, phenomenological method

\footnotetext{
'Portuguese Society for Existential Psychotherapy, Lisbon, Portugal 2ISPA-University Institute, Lisbon, Portugal

\section{Corresponding Author:}

Daniel Sousa, ISPA-University Institute, Rua Jardim do Tabaco 34, Lisbon I I49-04I, Portugal. Email: daniel.sousa@ispa.pt
} 


\section{Introduction}

Supervision is an international and multidisciplinary phenomenon (Cutcliffe, Hyrkäs, \& Fowler, 2011) with evaluative, formative, and regulatory aspects; is based on a collaborative relationship over time; and aims to advance the professional development of the supervisee (American Psychological Association [APA], 2014). In psychotherapy, supervision also includes the personal development of the supervisee/therapist (Watkins, 2012). The need for an evidence-based practice has been emphasized in the literature and is stressed in the APA (2014) Guidelines for Clinical Supervision in Health Psychology Service.

\section{What Are the Main Variables Identified?}

In a literature reviews of publications from the past decade, the main approaches considered included the following: (a) the supervisor's education/training, (b) the supervisor's personal development, (c) alliance; and (d) process.

One of the arguments that supports the relevance of researching the supervisor's education/training is based on the challenge presented by Worthington in 1987 (reissued in 2006) that supervisors do not become competent only by the accumulation of supervisory experience (Watkins, 2012; Worthington, 2006) or clinical practice (Keegan \& Hunsley, 2013). Knowledge of supervision does not imply that one knows how to supervise, much less how to supervise well (du Plock, 2009).

As for the supervisor's personal development, the relational dimension emerges as relevant and is considered to play a critical role in supervisory training. Security, trust, and respect are aspects identified in this dimension; and authenticity, presence, and honesty are defined as the supervisor's qualities that favorably influence successful supervision (Majcher \& Daniluk, 2009).

Alliance, which is considered to be nuclear and transtheoretical and is referred to as "the heart and soul of supervision" (Watkins, 2014b, p. 20), has been the dominant variable in supervision research. The most salient factors, such as (a) secure base/environmental facilitators; (b) empathy, genuineness, and positive reinforcement; (c) rupture/repair; (d) remoralization; (e) readiness and fitness of the supervisee; and (f) corrective emotional experience are considered to contribute to the establishment and maintenance of the alliance (Watkins \& Scaturo, 2013).

The main instruments for measuring alliance that were identified in the literature between 1990 and early 2013 consisted of the Supervisory Working Alliance Inventory (Watkins, 2014a; supervisor and supervisee versions); the Working Alliance Inventory (Watkins, 2014a; supervision version, in which 
bond and rapport emerged as the more frequent and relevant elements [Watkins, 2014b]); and the Supervisory Relationship Measure (supervisor's perspective; developed and validated by Pearce, Beinart, Clohessy, \& Cooper, 2013). The factors identified included (a) safe-base; (b) the supervisor's commitment; (c) the supervisee's contribution; (d) external influences (stress generating issues, evaluation-related issues, and previous experience of supervision); and (e) the supervisor's investment, thus reflecting the complexity of the concept of alliance in supervision. Some of the emerging factors in the measurement of the therapeutic alliance scales are clearly from the domain of the relationship. The fact that constructs sometimes appear unclear and indistinct is frequently mentioned in the literature (Pearce et al., 2013), and consequently, the quality of the construct's measurement (Stoltenberg \& McNeill, 2012) is likely justified by the complexity of these factors. Psychotherapeutic processes, in general, and supervision, in particular, are both relational in nature and thus understandable with respect to the influence of various factors.

Within the variable process, several domains have been studied, namely: (a) the therapeutic and supervisory relationship, (b) supervisee's anxiety, (c) conflict and counterproductivity, (d) therapeutic outcomes and process, (e) characteristics of the participants, (f) multicultural issues, (g) legal and ethical issues, (h) competence to supervise, and (i) other issues related to responsibility (Stoltenberg \& McNeill, 2012).

The main conclusions directly relevant to our study point to the relevance of the supervisor/supervisee relationship and its multifaceted influence on both the quality of the supervisory process and professional development of the supervisee (Worthen \& McNeill, 1996). From the supervisee's perspective, a good relationship is based on warmth, acceptance, respect, understanding, and trust; however, other factors may contribute to a positive or negative experience with supervision (Hutt, Scott, \& King, 1983). From the supervisor's perspective, the relationship should contribute to a good alliance by encompassing aspects that provide a platform for reflection on their own work regarding the development of empathy toward their supervisees, such as evaluation, feedback, openness, and flexibility in conflict management; additionally, the relationship should cultivate patience, stimulate the strengths of the supervisees and clarify the need for their development. A positive supervision experience must simultaneously integrate these aspects of the relationship and task management (Stoltenberg \& McNeill, 2012).

The anxiety of the supervisee is one of the factors that has been identified as important and not always harmful, as it can exhibit a strong effect on his or her professional development. An optimal level of anxiety (or activation) promotes a better performance rather than inhibits it (Stoltenberg \& McNeill, 
2012). With regard to conflict and counterproductivity, the main conclusions tell us that when the relationship is not experienced by the supervisee as promoting a safe environment, the therapeutic alliance may be negatively influenced (Gray, Ladany, Walker, \& Ancis, 2001; Stoltenberg \& McNeill, 2012).

The studies on the outcomes of supervision, which are directly related to the therapeutic process (supervisee-therapist/client), could improve if the gap between research and practice is reduced. It is essential to demonstrate that supervision influences the outcomes related to the client's progress and change (Watkins, 2011). The overvaluation of clinical outcomes in supervision entails unnecessary risks since these outcomes often imply weak causal logic and fail to identify the mechanisms of change (Reiser \& Milne, 2014). In a more integrative attempt, Swift et al. (2014) suggested that both the outcomes and client feedback be brought to the supervisory process to pursue an informed supervision, similar to the search for evidence-based practice in psychotherapy. This is a way to support clinical judgment, which benefits the client compared with supervision that does not integrate feedback (Stoltenberg $\&$ McNeill, 2012). As in psychotherapy and based on the idea that the psychotherapist's characteristics are predictive of results (Anderson, Ogles, Patterson, Lambert, \& Vermeersch, 2009), we should also consider the characteristics of the participants in evaluating supervision. These characteristics consist of personal factors, including beliefs, attitudes, life experience, personality, and interpersonal styles, as well as external aspects of learning contexts, clinical training, and professional practice (Falender \& Shafranske, 2014). The multicultural issues are related to diversity in the supervisory context (supervisor and supervisee) and the therapeutic context (supervisee/psychotherapist and client; Falender \& Shafranske, 2014). There are few empirical studies on the legal and ethical issues, competence to supervise, and management responsibility (Stoltenberg \& McNeill, 2012).

Conclusions regarding the various aspects of supervision reveal that its practice is not homogeneous and that studies of supervision are typically limited by the process variable (Watkins, 2014a). Qualitative studies could substantially contribute to the conceptualization, research, and practice of supervision because they generate comprehensive structures, promote wider perspectives, and strengthen knowledge on this topic. Ideally, they must respect the same quality criteria required for quantitative approaches (Watkins, 2014a). The use of qualitative studies in psychotherapy/supervision is necessary to the development of guiding principles for practice, as well as the application of qualitative meta-analysis and advancement of public policy reviews (Levitt, 2015). Supporting studies in personal development with a solid, evidence-based theory can also be beneficial for ensuring validity, reliability, and generalization (Barker \& Hunsley, 2013). 


\section{What Are the Main Identified Models?}

Several authors have proposed models that are more or less empirically supported that shift the focus from the supervisor's development and supervisee's development to the role of the supervisor and the corresponding relationship styles. One proposal is the discrimination model $(1979,1997)$ and another is the developmental model (1987). The first is built around the supervisor's role (teacher, counselor, and consultant) and focuses on areas in supervision (counseling performance skills, cognitive counseling skills, self-awareness, and professional behaviors). The second, on the contrary, does not adhere to a uniform scheme because its emphasis is on the developmental area, while the sharing of issues, behaviors, motivations, and perspectives on progress differs depending on the approach (whether it is cognitive or psychosocial development; Borders \& Brown, 2005). In Stoltenberg and McNeill's (2012) review, the main concern is the supervisee's development as it is prescribed in the interpersonal approach model (Ladany, Frielander, \& Nelson, 2005) and the integrative developmental model (Stoltenberg \& McNeill, 2012).

\section{Research on Group Supervision}

There is scarce literature on the topic of group supervision (Smith, Riva, \& Cornish, 2012). There seem to be few similarities between individual and group supervision; however, some specific issues emerge in the latter. The advantages often referred to include the existence of a wider range of perspectives and the enlargement of the clinical reference since the supervisees become aware of their colleagues' experiences and those of their clients, along with the supervisor's teachings. However, the supervisor has a disadvantage in group setting because it is more difficult to promote and conduct the supervisory process while simultaneously responding to the individual needs of each supervisee and maintain a good working relationship with the group. It is also important to consider the development of a supervisee's skills within the context of a diverse environment; for example, if the supervisor does not avoid conflicts within the group but instead offers the opportunity for conflict interactions to be constructive, he or she allows the supervisees to express themselves, and different points of view are considered and reflected (Ögren \& Sundin, 2009).

Guidance that informs practice is mostly absent from the literature, which raises ethical issues, among other problems (Smith et al., 2012). One way to ensure a well-planned, structured, and ethically protected group supervision is to implement the use of contracts. As a well-recognized element in individual supervision, a contract defines and clarifies the objectives, determines the roles and explicates the evaluative component of supervision (Smith, Cornish, \& Riva, 2014). 
Diversity/multiculturalism was also considered to be one of the relevant aspects of group supervision, which is ideally a self-reflective process and therefore enriched by various perspectives pertinent to clinical practice (Chin, Petersen, Nan, \& Nicholls, 2014).

\section{Existential Supervision: Proposals and Research}

As suggested by Craig, Voss, Cooper, and Correia (2016), existential psychotherapies are based on assumptions, such as the following: (a) human beings are oriented to and have the need for meaning and purpose; (b) human beings have the capacity for actualizing freedom and choice and for embracing responsibility for that freedom; (c) humans beings face inevitable limitations and challenges in their lives; (d) human being's subjective, phenomenological flow of experience is a central focus for psychotherapeutic work; and (e) human being's act of being-in-the-world-with-others is a fundamental aspect of being human.

There is scarce literature on existential supervision, although some conceptual and research efforts have been made. van Deurzen and Young's (2009) edition addresses the experiences of various authors on existential training and practice and offers several consistent arguments for considering existential supervision. Their work was a first attempt to systematize knowledge in existential supervision, highlighting the importance of research, and the transtheoretical possibilities of this perspective since all supervision is, to some extent, existential in nature. Some specific themes emerged suggesting how the practice of supervision can reach a coherent perspective within its existential, theoretical, and philosophical assumptions. The emergent themes are (a) being-in-the-world; (b) phenomenology; (c) dialogue; (d) love, care, and respect; (e) embodiment; (f) worldview, spirituality, and meaning; (g) responsibility and freedom; and (h) organizational context. The proposal is then to ensure that these themes form the structure of existential supervision.

According to Farber $(2010,2012)$, humanistic-existential supervision values the relationship and experiential depth in a pluralistic and integrative way, which is aligned with the 21 st-century competency-based framework. These experiential and interpersonal aspects (including depth) are central to humanistic approaches to promote intersubjective construction of meaning and appreciation for the "here and now," which in the supervisory context, helps supervisees address countertransference issues in therapy while developing personally and professionally (Krug \& Schneider, 2016). To offer a model for existential supervision, Sarah Pagdin (2013) stresses the transtheoretical possibilities that result from attending to the lived experience and the reported and embodied experiences of the people involved (therapists and 
clients), as well as the relationship centrality. One interesting issue she discusses is the idea of the supervisor's whole self being involved in the process, which may raise the questions of whether this aspect is a specific characteristic of this perspective and how this aspect influences supervision. To Spinelli (2015), existential supervision with an inclusive approach cannot avoid some overseeing issues related to its formative, normative, and restorative functions, but this approach also has distinctive features, such as its focus on the supervisee's experience of the encounter with the client and its ability to "open up the supervision-world space for an exploration," which classify it as a seeing-over approach.

With regard to research on existential supervision research, du Plock (2009) made a pioneering contribution in a study that aimed at identifying the essential structures from therapists' experiences of receiving and facilitating so-called existential supervision. He identified the following four dimensions common to both the supervisor and supervisee: (a) assistance/consideration offered to the supervisee, (b) support from a philosophical attitude, (c) promotion of a relational perspective, and (d) the role of the supervisor as a peer and mentor. The author focused on the possibility of being in a relationship based on cooperative reflection and used a nonauthoritative approach and exploration as the distinctive features of existential supervision. Other aspects worth mentioning include the centrality of the therapeutic alliance based on the relationship, as well as the encounter, and meaning attribution.

Although much work has already been performed in supervision research, a review of the literature highlights the need to expand and consolidate knowledge in this area. Qualitative methodologies are one possible way to achieve that goal.

Taking into consideration the research framework in supervision, the aim of this study was to explore the theme of clinical supervision from the supervisor's perspective, making note of his or her experience in practice informed by an existential approach, thus broadening knowledge in this field. We conducted a comprehensive analysis of the emerging themes from interviews with each participant, which were conducted using the phenomenological method in an overall structure represented by the eidetic dimensions and how they relate to each other.

\section{Methodology}

\section{Design}

Regarding the objectives of this study, we opted to use a qualitative methodology, which takes a comprehensive naturalistic approach and is focused on 
the assessment of meaning from the experiences of each participant. This choice is suitable for studying processes that occur over time, exploring complex issues and seeking to answer the questions of what and how rather than why (Ritchie \& Lewis, 2009). The descriptive phenomenological method recommended by Giorgi (Giorgi \& Sousa, 2010) was selected to analyze the interviews because it is a qualitative method supported by a theory of knowledge, requires accuracy for its application, and is aligned with the epistemological position of the researcher. As a result, this choice suits the purpose of this study.

\section{Participants}

The selection of participants was determined by their suitability and the relevance of their testimony about their experiences with regard to the likelihood of their contribution within the explored theme. Participants were selected in accordance with the criteria of a qualitative research validation framework (Sousa, 2014), taking advantage of the easier access of the SPPE (Portuguese Society for Existential Psychotherapy), which conducts group supervision in training contexts for psychotherapists. Three supervisors of SPPE were interviewed, one female and two male participants, with an average age of 44 years. One participant is a psychiatrist with 28 years of clinical experience and 10 years as a supervisor. The other two participants are clinical psychologists, and both have 14 years of clinical experience and 5 years and 7 years as supervisors. They are all psychotherapists with an existentialphenomenological perspective.

\section{Procedure}

We initially contacted people via e-mail to invite them to participate in the study and schedule interviews. The interviews were conducted by the study investigators at different places according to the preference of each participant. Before each interview, informed consent was provided. The use of a voice recorder, as well as the purpose of the study and method of analysis that would be applied later, were all explained. Before the recording commenced, the participant was offered an opportunity to ask questions and was informed about requesting further clarification at the end of the interview. Once the voice recorder was on, each participant was asked to describe, in as much detail as possible, their supervisory experience from the supervisor's perspective. The average time for each interview was 48 minutes. 


\section{Instruments}

The phenomenological interview was the instrument used to collect the data for this study. This type of interview differs from other interviews in the underlying theory that supports it and in the purpose of its use in relation to the content of the data to be collected and later analyzed. This type of interview aims to produce conceptually distinctive knowledge (Kvale, 1996). As opposed to structured interviews or closed questionnaires, which aim mainly to test hypotheses, the phenomenological interview exhibits an exploratory, interrelational and dialectical style (Giorgi \& Sousa, 2010).

\section{Results}

\section{Overall Structure: Key Constituents (PI, P2, and P3)}

The existential-phenomenological approach to supervision is based on the centrality of the relationship and the responsiveness the supervisor offers to the unique features and needs of each supervisee. Insecurity of supervisees emerges as a common difficulty; thus, the promotion of a secure space is important for overcoming anxieties that can lead to avoidances or even omissions. For supervisees, supervision is a professional and personal development space, in which the paths that lead to clinical practice are explored. Supervision is also a space for knowledge integration, which enables the connection between knowledge and know-how. Supervision in the existential-phenomenological approach is a collaborative process of coreflection, in which the contribution of supervisees is valuable for discussion and the supervisees are encouraged to broaden their perspectives in a working partnership. It is possible to identify a balance between relational and clinical aspects in the focus of supervision, emphasizing the practical aspects over the background level for theory. An opening space is created for a discovery process that fosters personal and professional progress, spurred by permanent self-questioning promoted by the supervisor, offering him or herself as a foundational model. As a result of the opening attitudes and questions, the groundwork for the availability to integrate different perspectives is built, which is a recognized advantage of group supervision. The supervisor has an important responsibility to adjust expectations that should facilitate the integration of new prospects and assist supervisees in facing their own limitations. Supervision in the existential-phenomenological approach also serves as a learning space for the supervisor. From his or her perspective, clinical practice supports the practice of supervision and supervision incorporates the influence of the supervisor's experience as a supervisee while promoting the ability to respond to 
Table I. Empirical Variations (Examples): PI, P2, and P3.

\begin{tabular}{|c|c|c|c|}
\hline $\begin{array}{l}\text { Centrality of } \\
\text { relationship }\end{array}$ & Responsiveness & $\begin{array}{l}\text { Openness to not } \\
\text { knowing }\end{array}$ & $\begin{array}{l}\text { Humility, } \\
\text { authenticity, and } \\
\text { consistency }\end{array}$ \\
\hline $\begin{array}{l}\text { “. . . ) we are } \\
\text { asking people } \\
\text { to tell us about } \\
\text { the parts that } \\
\text { are not so good } \\
\text { about what } \\
\text { you're doing ( . } \\
. \text { ) where are you } \\
\text { feeling limitations } \\
\text { and difficulties. (. } \\
\ldots \text { ) it's important } \\
\text { ( . . . ) that there } \\
\text { is a relational } \\
\text { ground that } \\
\text { allows this to } \\
\text { happen.” P2 } \\
\text { “ ( . . ) It's } \\
\text { necessary to wait } \\
\text { for them to be } \\
\text { prepared to self- } \\
\text { questioning.” PI }\end{array}$ & $\begin{array}{l}\text { “( . . ) within the } \\
\text { complexity of } \\
\text { being a person } \\
\text { and the way we } \\
\text { respond to them } \\
\text {. . . the particular } \\
\text { way, to the person } \\
\text { who is in front of } \\
\text { us, right?” P3 } \\
\text { "( . . ) some people } \\
\text { considered a little } \\
\text { more difficult to } \\
\text { handle ... I didn't } \\
\text { feel any of that } \\
\text { in supervision; } \\
\text { on the contrary, } \\
\text { I felt it was only } \\
\text { a matter of being } \\
\text { careful when } \\
\text { approaching } \\
\text { them.” P2 }\end{array}$ & $\begin{array}{l}\text { “I don't ask ... } \\
\text { some supervisors } \\
\text { do ... well, not } \\
\text { in this Society, } \\
\text { but in some } \\
\text { other places, the } \\
\text { supervisors ask } \\
\text { for the clinical } \\
\text { case in advance } \\
\text {... so they can } \\
\text { have a previous } \\
\text { appreciation. I } \\
\text { don't want any } \\
\text { case, I want to be } \\
\text { challenged in that } \\
\text { moment ...” P2 } \\
\text { “( ... ) Un-knowing } \\
\text { is, sometimes, an } \\
\text { attitude, I mean, } \\
\text { a humble } \\
\text { attitude.” P3 }\end{array}$ & $\begin{array}{l}\text { “ . . ) we are } \\
\text { people in our } \\
\text { complexity as } \\
\text { people, failures, } \\
\text { nonsenses. } \\
\text {. hmm . . } \\
\text { doubts, fears, } \\
\text { and insecurity } \\
\text { and in that } \\
\text { field, we are } \\
\text { as patients as } \\
\text { our patients, } \\
\text { because we all } \\
\text { are people.” P3 } \\
\text { "That is what I } \\
\text { try to convey } \\
\text { even more in } \\
\text { my supervisions, } \\
\text { hey, be peaceful } \\
\text { at what you } \\
\text { don't know.” PI }\end{array}$ \\
\hline
\end{tabular}

emerging needs. Humility, authenticity, consistency, and openness to uncertainty are revealed to be supervisor qualities that define his or her stance in relation to the existential-phenomenological approach that informs his or her practice (Table 1). To the supervisor, pleasure and challenge are present throughout the process, encouraging him or her to face each supervision experience as unique (Figure 1 .

\section{Discussion}

By taking a panoramic perspective to assess the key constituents or eidetic dimensions and determine how they relate, a dynamic temporal-spatial configuration is presented, which is fed, nourished, and revitalized by the relationship and supervisor's responsiveness. This configuration entails (a) a situated starting point (a horizon of expectations), (b) an intermediate space of experiences (the process), and (c) a space-product (in an extended present and future horizon). 


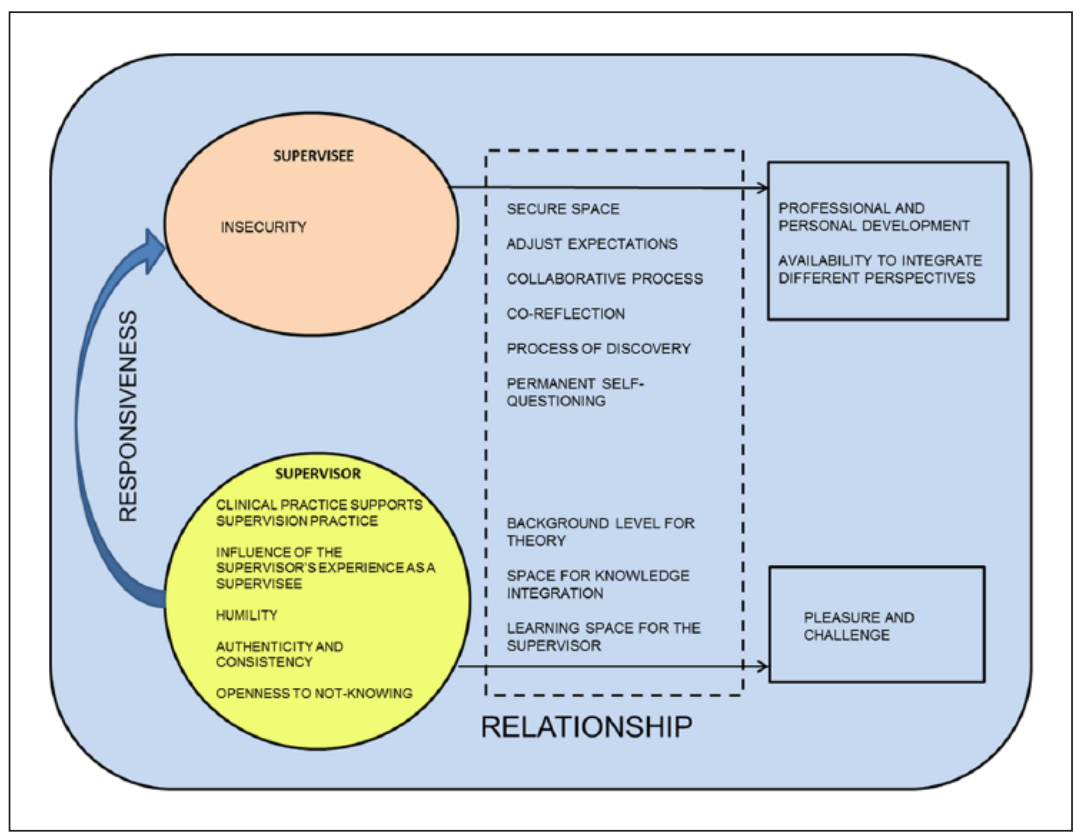

Figure I. Overall structure.

\section{A Horizon of Expectations}

When beginning a supervision process, four actors (supervisors and supervisees) share the ontological quality of human beings facing the same data of existence; however, at the ontic level, some aspects are revealed that will influence how the process develops, particularly the situated starting point. From an analysis of the descriptions of the participants, it is evident that the insecurity felt by supervisees at the beginning of supervision is related to the fact that they are initiating the psychotherapeutic activity in the existential approach. This aspect stands out and significantly influences how the supervisor will address the supervisory situation by establishing the conditions for the professional development of the supervisees and simultaneously consider the regulatory aspect of psychotherapeutic practice with regard to its ethical and clinical dimensions. Compared with the supervisee, the supervisor has a broader experience because his or her clinical knowledge results from psychotherapeutic practice and the experience of having been a supervisee. $\mathrm{He}$ or she is attentive to the needs of the group, considering each supervisee's uniqueness, acting responsively and creating space for the encounter. Rollo 
May refers to the human encounter as a significant powerful moment, which is connected to the experience of looking at another human being with a degree of fascination, a type of unexpected vividness, and a recognition of the presence of the self-other that amazes and arouses our own presence as being (May, Angel, \& Ellenberger, 1958). The concept of presence is an ontological recognition of being in relation to another being, thus allowing one to marvel and generate empathy, promoting openness (paths), and interactions that Schneider calls awe (Schneider, 2007). It seems that supervisors also intend to promote a secure space from the centrality of the relationship with the supervisees. Supervisors expressed the following sentiments: "if we take care of the relationship (supervisor-supervisee), then everything can grow from there ... " or "a relaxed environment is an environment where people feel good and where people are not afraid to expose themselves because they will not be criticized." However, these concepts of presence and secure space also constitute the process of pushing boundaries, step-by-step. Perceiving themselves in such safe environments, supervisees can be pushed to reflect about themselves and the relationships they have with their clients. As expressed by one supervisor,

We push the boundary a little more and try to determine whether the person is okay and whether she accepts it or not. If she accepts, it's a sign that she's prepared to go a little further, that is, I can question her more and help her to be more self-reflective about her behavior.

By being responsive, the supervisor helps the supervisee develop empathy and enhance his metacognitive skills, which are crucial in the psychotherapy training process (Fauth, Gates, Vinca, Boles, \& Hayes, 2007). In addition to the supervisor's experience, there are some personal qualities, such as humility, authenticity, consistency, and openness to uncertainty, which are developed and valued by the existential approach, which informs how the supervisor will relate to the supervisee(s) and become the facilitator of an open coconstructive process. The aspects that relate to the personal development of the supervisor are consistent with the attributes of genuineness, honesty, and presence, which are qualities that are considered to be beneficial for successful supervision (Majcher \& Daniluk, 2009). Thus, the horizon of expectations is more like a direction to which paths converge, which is founded and defined through the participation of both parties, mediated by the relationship rather than a standard process, predefined, and suitable to all supervisees in pursuit of the ultimate objective of supervision, namely, development in preparation for professional psychotherapy practice. 


\section{The Process}

In the process - the intermediate space of experiences - the type of response given to the needs that arise during the time of supervision is disclosed. Given the perception of supervisee insecurity, promotion of a safe space is crucial to allow them to explore possibilities and discover their identities as psychotherapists, relying on the supervisor, on the group and on themselves to avoid the omission of information and exposure of vulnerabilities through compromising questions. This relationship between the perception of safety and optimal learning was identified in a study by Yourman and Farber (1996), which concluded that the decrease in the perception of safety negatively influences optimal learning. The literature also suggests that trust and security are associated with the variables of conflict and counterproductivity, especially in group supervision, and that when these features are absent, they have a negative influence on the alliance (Webb \& Wheeler, 1998). Being responsible for guiding the process, how will the supervisor promote conditions that will result in the creation of a perceived safe space? Supported by an accepting attitude, empathy, congruence, respect, care, and flexibility, and the relational ground that establishes the alliance and maintains cohesion in group supervision, the supervisor adjusts supervisees' expectations so that unrealistic objectives are not idealized. Using the metaphor of the convergent paths, we recall that the supervisor's task is to take the initial steps and be aware of the direction in which the supervisee is heading. From here, the supervisor will continue along a shared path that has been simultaneously revealed and discovered in a collaborative, coreflected process. Existential supervisors seem to focus on creating a space of mutual responsibility in which to construct meaning from the clinical discussion, especially with regard to cases and the supervisee's doubts. One of the supervisors/participants said, "I strive to follow a collaborative process, which is to listen to everyone's contribution. Let's think, how can we get ourselves to do this in practice?" In existential group supervision, all members play an active role in commenting and proposing ideas about the case being discussed. To this end, the supervisor wishes to promote a space in which meaning is created through the use of an intersubjective space. Illustrating this point, another supervisor/participant said, "a construction is a coconstruction that I also think is very close to the existential approach." Along the way, the supervisor and supervisee will assess how they experience being in supervision and also, in the supervisee's case, how they experience being with patients in the psychotherapeutic processes, both in a permanent self-questioning and in a coconstructive dynamic. At this point, we highlight the crucial role of the supervisor's responsiveness. Responsiveness means the supervisor has the capacity to empathically 
recognize and respond to the specific needs of that particular supervisee. The supervisors/participants often mentioned, "I would say that I make clinical decisions in terms of supervision rather than the approach I take with that particular supervisee." The appreciation of relational aspects is a central feature of the existential approach; however, the supervisor also focuses on clinical issues, meaning that there is some concern about not only how the supervisee relates to the patient but also how he or she is conducting the therapeutic process. This situation is clearly recognizable in the training context, according to the participants. Regarding the existential perspective and appreciation of the relational aspects, Spinelli (2007) stated that the individual only emerges and appropriates their distinctive self through the relationship and not the opposite, as assumed by most conceptual models in psychotherapy. This assumption is also supported by psychotherapy research since the relationship emerges as one of the determining factors for the development of the therapeutic process, particularly in determining how the methods and techniques will translate to results (Norcross, 2002; Norcross \& Goldfried, 2005; Norcross \& Lambert, 2014). The approach of theoretical and methodological clarifications is also recognized as a necessity for supervisees that allows for constant epistemological updating toward clinical applications. This broader focus is consistent with the conclusions of Hutt et al. (1983) and Stoltenberg and McNeill (2012), who state that successful supervision must simultaneously integrate aspects of both the relationship and task. In occupying a space for knowledge integration, existential supervision also serves as a learning opportunity for the supervisor. Relying on the attitudes of openness and discovery and sustained by the supervisor's availability for the relationship, the process of supervision integrates theoretical and clinical aspects and applies them to the practice of psychotherapy and the diversity of group contributions. The process of acknowledgment is multidirectional and multidimensional because the supervisee strengthens learning and the respect for integrating others' perspectives and the supervisor enriches his or her experience, despite some asymmetry. Some considerations noted in the literature regarding the supervisor's personal and professional development are stressed in this study; for example, the idea that the amount of clinical experience is not the only determinant for competency (APA, 2014; du Plock, 2009; Keegan \& Hunsley, 2013; Watkins, 2012; Worthington, 2006).

Due to the relevance of considering the supervisees' individual situations and characteristics, we propose the integration of the deliberate practice method with existential clinical supervision. Deliberate practice is a method of training used in several professional areas that experts - top performers - use to develop their know-how. Deliberate practice is currently being introduced to psychotherapy and is a promising area of training 
(Rousmaniere, Goodyear, Miller, \& Wampold, 2017). Deliberate practice can be integrated into the classical types of supervision and entails "repetitively practicing specific skills with continuous corrective feedback; reviewing videos of therapy sessions and repeatedly role-playing to identify mistakes made in videotaped sessions to address knowledge deficits specific to the therapist; working exactly at the therapist's performance threshold" (Rousmaniere et al., 2017, p. 9). This method requires solo training of the supervisee outside the context of supervision and sessions. Solo training - which should be recorded - emphasizes the relational areas that the supervisee and supervisor agree are in need of further development. This serves as a way to develop the supervisee's sense of self-reflection and to practice interacting with clients. At the same time, solo training can be a very idiosyncratic type of training.

\section{Extended Present and Future Horizon}

The concept referred to as space-product, in the temporal-spatial configuration that summarizes the structure of existential supervision, extends beyond the process of supervision. By this, we mean that the supervisor and supervisees are part of a personal and professional transformation process that allows them to explore in themselves unfamiliar, or even feared, dimensions and is focused on development in preparation for psychotherapy practice. Spaceproduct remains a significant part of supervision because it is integrated in each participant's experience and goes beyond the process since it is not limited to the supervision context. More than seeing this as an outcome, which points to some finished result, space-product can be understood as a new quality that serves the future. Space-product reflects the supervisee's personal and professional development, in which a growing attitude toward integrating different perspectives is evident. We also want to stress the gains in terms of both enjoyment and challenge that stimulate and color each supervisory process, aspects which van Deurzen and Young (2009) highlight and recommend in any approach to supervision, and reflect the personal investment of the supervisor. This work occurs in a coconstructive, relational, respectful, accepting, caring, and flexible scenario. In both cases, (for the supervisor and supervisee), the space-product is continuity.

\section{Conclusion}

The results of this study, translated into an overall structure of meaning, are consistent with several current findings in the literature on psychotherapy supervision, including the most widely recognized and agreed on elements of 
the APA guidelines. When one considers the APA (2014) definition of supervision, which has been developed from the evidence-based practice paradigm, similar to the guidelines for psychotherapy, the first highlighted aspect is the collaborative relationship and its influential character.

The concept of responsiveness and how it contributes to successful supervision is also a relevant consideration and is closely linked to relationship qualities. The emergence of the eidetic dimension of responsiveness is consistent with Friedlander's (2015) discussion, which stresses the importance of the adequacy of the supervisor in matching the characteristics of the supervisees that are associated with the alliance maintenance, breakdown and repair, both in the supervisory and psychotherapeutic processes. The evidence that a particular approach is more effective than another is nonexistent; thus, we agree with Watkins (2012), who stresses the importance of including responsiveness as a variable in supervision research.

Again, the findings demonstrate considerable similarity to the findings in psychotherapy research, particularly with regard to transtheoretical issues such as responsiveness (Norcross \& Wampold, 2011). The dimensions identified as integrating existential supervision in du Plock's (2009) study, although they were presented differently in this article, can also be identified in the overall structure of meanings emergent in this study, particularly the distinctive features - the centrality of the relationship, collaborative process, and coreflection.

The aspects of the dimension du Plock refers to as support from a philosophical attitude have been considered by us to be resultant qualities of the supervisor's attitude toward the theoretical perspective that inform his or her practice. The results also revealed that the experience of the existential supervisory process falls within the seeing-over perspective rather than overseeing perspective as well as fulfills the regulatory criteria, training and restorative functions, meeting Spinelli's (2015) proposal. For Spinelli, the seeing-over perspective is an integrative aspect of existential supervision that can be incorporated into other theoretical models, mostly dependent on the overseeing perspective. By trying to relate the overall structure of emergent meanings to the aforementioned proposal of van Deurzen and Young (2009), we identified several aspects of proximity between the dimensions identified in this study and the emerging themes from the collection of existential supervisors' experiences; however, the comparisons are limited because the methods and objectives leading to the findings in both cases are different. Still there is a remarkable convergence in the emphasis on the care for the being-in-the-world of the other and on the role of the truth as a guide in the supervision practice.

There was no emergence of any dimension linked to the increase of difficulties for the supervisor in group supervision contexts, contrary to the suggestions of several approaches in the literature. 
The results also support some criticisms of the literature regarding the relevance of the focus of the investigation; particularly; the tendency toward overvaluation of the variable outcomes associated with the therapeutic process (Reiser \& Milne, 2014), through the absence in the results of any corresponding theme. Since the method for analysis in this study was appropriate for identifying essential, invariant dimensions, there was no emergent constituent associated with levels of success or effectiveness of the therapeutic processes practiced by the supervisees.

This study contributed to the understanding of supervision, highlighting the importance of responsiveness, a fundamental aspect acknowledged in psychotherapy. As to the centrality of relationship, we believe that this study strengthens the conclusions offered in the literature identifying this aspect as the main component for success in all areas of the supervisory process. The supervisor models presence, promoting emotional maturity, which is aligned with the existential-humanistic perspective and is supported by research, stressing the relevance of experiential and interpersonal aspects of supervision (Krug \& Schneider, 2016). All other eidetic dimensions, which are constituents of the overall structure of meaning, are relevant and related to supervision. The observed dimensions suggest a dynamic structure resulting from a balance between formative and regulatory aspects, with a clear emphasis on relational issues.

\section{Recommendations and Limitations}

The most obvious limitation is the use of one view, that of the supervisor. It would be interesting to perform a thorough analysis of supervisory experience with supervisees to obtain another perspective of the other elements in this shared process and make note of convergences or divergences. Another limitation is that the described experiences are related to group training contexts. It would then be valuable to conduct studies in nontraining contexts, whether in group or individual contexts. Would the observed dimensions, including responsiveness, be positively related to greater inexperience and the supervisees' stage of development? Or would they emerge as fundamental aspects of the interrelationship, regardless of the experience of clinical practice?

\section{Declaration of Conflicting Interests}

The author(s) declared no potential conflicts of interest with respect to the research, authorship, and/or publication of this article. 


\section{Funding}

The author(s) received no financial support for the research, authorship, and/or publication of this article.

\section{ORCID iD}

Daniel Sousa (iD) https://orcid.org/0000-0001-8213-4616

\section{References}

American Psychological Association. (2014). Guidelines for clinical supervision in health service psychology. Retrieved from http://www.apa.org/about/policy/ guidelines-supervision.pdf

Anderson, T., Ogles, B., Patterson, C., Lambert, M., \& Vermeersch, D. (2009). Therapist effects: Facilitative interpersonal skills as a predictor of therapist success. Journal of Clinical Psychology, 65, 755-768.

Barker, K., \& Hunsley, J. (2013). The use of theoretical models in psychology supervisor development research from 1994 to 2010: A systematic review. Canadian Psychology, 54, 176-185.

Borders, L. D., \& Brown, L. L. (2005). Supervision models and principals. In The new handbook of counseling supervision (pp. 1-17). New York, NY: Taylor \& Francis.

Chin, J., Petersen, K., Nan, H., \& Nicholls, L. (2014). Group supervision as a multicultural experience: The intersection of race, gender, and ethnicity. In C. Falender, E. Shafranske \& C. Falicov (Eds.), Multiculturalism and diversity in clinical supervision: A competency-based approach (pp. 255-272). Washington, DC: American Psychological Association.

Craig, M., Voss, J., Cooper, M., \& Correia, E. (2016). Existential psychotherapies. In D. Cain, K. Keenan \& S. Rubin (Eds.), Humanistic psychotherapies: Handbook of research and practice (2nd ed.) (pp. 283-317). Washington, DC: American Psychological Association.

Cutcliffe, J., Hyrkäs, K., \& Fowler, J. (Eds.). (2011). Routledge handbook of clinical supervision: Fundamental international themes. London, England: Routledge.

du Plock, S. (2009). An existential-phenomenological inquiry into the meaning of clinical supervision: What do we mean when we talk about "existential-phenomenological supervision"? Existential Analysis: Journal of the Society for Existential Analysis, 20, 299-318.

Falender, C., \& Shafranske, E. (2014). Clinical supervision: The state of the art. Journal of Clinical Psychology: In session, 70, 1030-1041.

Farber, E. W. (2010). Humanistic-existential psychotherapy: Competencies and the supervisory process. Psychotherapy, 47, 28-34.

Farber, E. W. (2012). Supervising humanistic-existential psychotherapy: Needs, possibilities. Journal of Contemporary Psychotherapy, 42, 173-182.

Fauth, J., Gates, S., Vinca, M. A., Boles, S., \& Hayes, J. (2007). Big ideas for psychotherapy training. Psychotherapy: Theory, Research, Practice, Training, 44, 384-391. 
Friedlander, M. (2015). Use of relational strategies to repair alliance ruptures: How responsive supervisors train responsive psychotherapists. Psychotherapy, 52, 174-179.

Giorgi, A., \& Sousa, D. (2010). Método fenomenológico de investigação em psicologia [Phenomenological method of investigation in psychology]. Lisbon, Portugal: Fim de Século.

Gray, L. A., Ladany, N., Walker, J. A., \& Ancis, J. R. (2001). Psychotherapy trainees' experience of counterproductive events in supervision. Journal of Counseling Psychology, 48, 371-383.

Hutt, C., Scott, J., \& King, M. (1983). A phenomenological study of supervisees' positive and negative experiences in supervision. Psychotherapy: Theory, Research \& Practice, 20, 118-123.

Keegan, K., \& Hunsley, J. (2013). The use of theoretical models in psychology supervisor development research from 1994 to 2010: A systematic review. Canadian Psychology, 54, 176-185.

Krug, O., \& Schneider, K. (2016). Research and support for the existential-humanistic training approach: APA supervision essentials for existential humanistic therapy. Washington, DC: American Psychological Association.

Kvale, S. (1996). Interviews: An introduction to qualitative research interviewing. London, England: Sage.

Ladany, N., Friedlander, M. L., \& Nelson, M. L. (2005). Critical events in psychotherapy supervision: An interpersonal approach. Washington, DC: American Psychological Association.

Levitt, H. (2015). Qualitative psychotherapy research: The journey so far and future directions. Psychotherapy, 52, 31-37.

Majcher, J., \& Daniluk, J. (2009). The process of becoming a supervisor for students in a doctoral supervision training course. Training and Education in Professional Psychology, 3, 63-71.

May, R., Angel, E., \& Ellenberger, H. (Ed.). (1958). Existence. A new dimension in psychiatry and psychology. New York, NY: Basic Books.

Norcross, J. (Ed.). (2002). Relationships that work: Therapist contributions and responsiveness to patients. Oxford, England: Oxford University Press.

Norcross, J., \& Goldfried, M. (Eds.). (2005). Handbook of psychotherapy integration. Oxford, England: Oxford University Press.

Norcross, J., \& Lambert, M. (2014). Relationship science and practice in psychotherapy: Closing commentary. Psychotherapy, 51, 398-403.

Norcross, J., \& Wampold, B. (2011). What works for whom: Tailoring psychotherapy to the person. Journal of Clinical Psychology: In Session, 67, 127-132.

Ögren, M.-L., \& Sundin, E. (2009). Group supervision in psychotherapy: Main findings from a Swedish research project on psychotherapy supervision in a group format. British Journal of Guidance \& Counseling, 37, 129-139.

Pagdin, S. (2013). An existential phenomenological model of supervision. Existential Analysis, 24, 142-152.

Pearce, N., Beinart, H., Clohessy, S., \& Cooper, M. (2013). Development and validation of the supervisory relationship measure: A self-report questionnaire for use with supervisors. British Journal of Clinical Psychology, 52, 249-268. 
Reiser, R., \& Milne, D. (2014). A systematic review and reformulation of outcome evaluation in clinical supervision: Applying the fidelity framework. Training and Education in Professional Psychology, 8, 149-157.

Ritchie, J., \& Lewis, J. (2009). Qualitative research practice: A guide for social science students and researchers. London, England: Sage.

Rousmaniere, T., Goodyear, R. K., Miller, S. C., \& Wampold, B. E. (2017). The cycle of excellence: Using deliberate practice to improve supervision and training. Hoboken, NJ: Wiley-Blackwell.

Schneider, K. (Ed.). (2007). Existential-integrative psychotherapy: Guideposts to the core of practice. London, England: Routledge.

Smith, R., Cornish, J., \& Riva, M. (2014). Contracting for group supervision. Training and Education in Professional Psychology, 8, 236-240.

Smith, R., Riva, M., \& Cornish, J. (2012). The ethical practice of group supervision: A national survey. Training and Education in Professional Psychology, 6, 238-248.

Sousa, D. (2014). Validation in qualitative research: General aspects and specificities of the descriptive phenomenological method. Qualitative Research in Psychology, 11, 211-227.

Spinelli, E. (2007). Practising existential psychotherapy: The relational world. London, England: Sage.

Spinelli, E. (2015). On existential supervision. Existential Analysis, 26, 168-178.

Stoltenberg, C., \& McNeil, B. (2012). Supervision: Research, models and competence. In N. Fouad (Ed.), APA handbook of counseling psychology: Theories, research and methods (Vol. 1, pp. 295-327). Washington, DC: American Psychological Association.

Swift, J., Callahan, J., Rousmaniere, T., Whipple, J., Dexter, K., \& Wrape, E. (2014). Using client outcome monitoring as a tool for supervision. Psychotherapy, 52, 180-184.

van Deurzen, E., \& Young, S. (Eds.). (2009). Existential perspectives on supervision: Widening the horizon of psychotherapy and counselling. Basingstoke, England: Palgrave McMillan.

Watkins, E. (2011). Does psychotherapy supervision contribute to patient outcomes? Considering thirty years of research. The Clinical Supervisor, 30, 235-256.

Watkins, E. (2012). Educating psychotherapy supervisors. American Journal of Psychotherapy, 66, 279-307.

Watkins, E. (2014a). Clinical supervision in the 21st century: Revisiting pressing needs and impressing possibilities. American Journal of Psychotherapy, 68, 251-272.

Watkins, E. (2014b). The supervisory alliance: A half century of theory, practice, and research in critical perspective. American Journal of Psychotherapy, 68, 19-55.

Watkins, E., \& Scaturo, D. (2013). Toward an integrative, learning-based model of psychotherapy supervision: Supervisory alliance, educational interventions, and supervisee learning/relearning. Journal of Psychotherapy Integration, 23, 75-95.

Webb, A., \& Wheeler, S. (1998). How honest counselors dare to be in the supervisory relationship? An exploratory study. British Journal of Guidance and Counselling, 26, 509-524.

Worthen, V., \& McNeill, B. (1996). A phenomenological investigation of "good" supervision events. Journal of Counseling Psychology, 43, 25-34. 
Worthington, E. (2006). Changes in supervision as counselors and supervisors gain experience: A review. Training and Education in Professional Psychology, S(2), 133-160.

Yourman, D., \& Farber, B. (1996). Nondisclosure and distortion in psychotherapy supervision. Psychotherapy: Theory, Research, Practice, Training, 33, 567-575.

\section{Author Biographies}

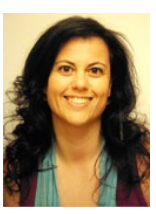

Sara Silva is a clinical psychologist and existential psychotherapist in training in the Portuguese Society for Existential Psychotherapy. Research interests include supervision in psychotherapy, focusing, and human development.

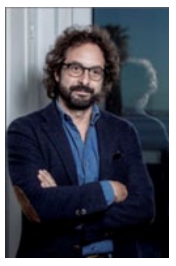

Daniel Sousa is the director of the ISPA Clinic (university-based clinic) and an assistant professor at ISPA - University Institute. He is a founding member of the Portuguese Society of Existential Psychotherapy. He is the coordinator of the Research Center in Clinical Psychology and Psychotherapy, where he has carried out research on the processes of change in psychotherapy, on the therapeutic relationship and feedback systems in the context of therapeutic process. Presently, he is also interested on the application of routine outcome monitoring in psychotherapy. 